\title{
An Algorithm for Non-intrusive In-Situ Efficiency Estimation of Induction Machines Operating with Unbalanced Supply Conditions
}

\author{
Arbi Gharakhani Siraki, Student Member, IEEE, Chetan Gajjar, Student Member, IEEE, Mohamed \\ Azeem Khan, Member, IEEE, Paul Barendse, Member, IEEE, and Pragasen Pillay, Fellow, IEEE
}

\begin{abstract}
The development of an in-situ efficiency estimation technique is a challenging task where the lowest level of intrusion and the highest possible accuracy is required. In this paper a new algorithm is discussed for in-situ efficiency estimation of induction machines under unbalanced power supplies. Prior work in literature has concentrated on balanced supplies. In addition, to have a non-intrusive speed measurement, a specific adaptive nonlinear algorithm is applied for extraction of the speed dependent current harmonics from the measured current signal. A similar algorithm is used to extract the symmetrical components from the current and voltage signals to handle the unbalanced supply conditions. Experimental results with two different machines are used to prove the effectiveness and generality of the proposed method. Measurement error analysis as well as repeatability tests have been done to determine the credibility of the proposed method.
\end{abstract}

Index Terms-Evolutionary algorithm, induction motor, insitu efficiency estimation, non linear adaptive filter, unbalanced supply, error analysis, repeatability test

\section{INTRODUCTION}

$\mathrm{D}$ EMAND side energy management is one of the many ways to cope with the increasing demand for energy in industrialized countries. Improving the efficiency of electrical motors and more specifically the induction motors is one aspect where there is a significant potential for energy savings due to the large number of electrical motors in the electrical power system of industrialized and developing countries [1].

The importance of efficient operation of the electrical motors became more evident by enactment of the Energy Policy Act of 1992 [2], which focuses on the efficient operation of the motors. As a result of this act, manufactures

Manuscript received Nov 17, 2011. This work was supported in part by the R\&D program of the NSERC Chair entitled Energy efficiency in electrical machines for small renewable energy production systems established in 2009 at "Concordia University"

A. Gharakhani Siraki is with the Electrical and Computer Engineering Department of Concordia University, Montreal, QC H3G 1M8, Canada (email: arbi@ieee.org).

C. Gajjar, M. A. Khan, and P. Barendse are with the Department of Electrical Engineering, University of Cape Town, Cape Town 7701, South Africa (e-mail: Gajjar.chet@gmail.com; Azeem.Khan@uct.ac.za; paul.barendse@uct.ac.za)

P. Pillay is with the Electrical and Computer Engineering Department of Concordia University, Montreal, , QC H3G 1M8, Canada and also with the University of Cape Town, Cape Town 7701, South Africa (e-mail: pillay@encs.concordia.ca). have to construct and industries have to buy more efficient motors both for new installations and replacement purposes.

With the goal of encouraging the industrial sector to undertake the demand side energy management techniques in their plants, the US Department of Energy developed a software tool named " Motor Master + " [3] which facilitates management of motors in an industrial facility. It contains features which makes it possible to identify the motors with poor efficiencies, calculate life time energy savings (in case of replacement of an old motor with a new one) and make decisions over replacement or repair of an existing motor.

Energy saving calculations and the relevant decisions, such as replacement of an existing motor, are strongly dependent on an accurate knowledge of the motor efficiency. The efficiency of an induction motor can be affected by many factors such as supply voltage unbalance [4], over or under voltage conditions [5], non critical motor internal faults, the effects of the rewinding and repair of the motor or simply due to over or under loading (due to inappropriate sizing of the motor) conditions. Therefore in-situ efficiency monitoring of the installed motors is a necessity to detect the motors with poor efficiencies and take the appropriate action. For the purpose of this paper non intrusive refers to electrical measurements at the terminals only with no mechanical measurement in a particular speed.

Due to this necessity, numerous methods have been proposed for in-situ efficiency estimation of induction machines. These methods can be briefly classified as follows:

\section{Slip method}

- Current method

- Simplified equivalent circuit method (such as the Oak Ridge National Laboratory method which is known as ORNEL96 [6]).

- Simplified loss segregation method (such as the method of Ontario Hydro [7]).

Simplified air gap torque method [8]

- Optimization based methods[9]-[16]

Most of these methods are developed for the balanced supply conditions. However, in reality some level of voltage unbalances generally exist in the industry and can sometimes be severe. Unbalanced supplies can exist due to different reasons such as [17, 18]:

- Incomplete transposition of transmission lines

- Open delta transformers 
- Blown fuses on three phase capacitor banks

- Unequal distribution of single phase loads

- Operation of the single phase loads at different times

- Defective transformers in power systems

Based on the NEMA MG1 standard, induction motors can operate under up to $5 \%$ unbalance voltages [17]. In real conditions and specifically in weak power systems, the voltage unbalance factor can be even more severe. Based on [17, 18], an unbalanced power supply occurring with a combination of over or under voltage conditions, can significantly affect the working efficiency. Therefore, it is essential to use a method which is specifically developed to deal with these conditions. This will allow more accurate estimation of the efficiency under real industrial conditions.

None of the first four methods are accurate for in-situ efficiency estimation under unbalanced supplies. The non intrusive air gap torque method [8] considers the effect of the unbalanced voltages on the net produced torque. However, the accuracy of this method is significantly dependent on the accurate measurement of the stator's resistance at the operating temperature, the accurate assumption of the no load losses and the accurate assumption of the stray losses at different loading conditions. Optimization based methods show promise where the efficiency of the machine is calculated based on estimation of the parameters of the equivalent circuit with help of an evolutionary based search algorithm (ex. Genetic Algorithm).

Based on a literature review, [19] is the only work that combined an optimization based technique with the equivalent circuit method to deal with the efficiency estimation problem under unbalanced supply conditions. However, there are serious concerns about convergence of this algorithm to a unique set of solutions due to a higher number of unknowns with respect to the known parameters.

In this paper, a new non intrusive in-situ efficiency estimation algorithm is presented in section II. Then in the section III, a non intrusive speed estimation technique which can be used in an efficiency estimation process is proposed and the obtained results are compared with the experimental measurements. In the proposed method the speed data is extracted from current dependent speed harmonics with help of a specific non linear adaptive algorithm (developed in [20] for biomedical applications) and the frequency spectrum analysis of the residual signal.

In section IV, it is shown that the same non linear adaptive algorithm can be used to extract the symmetrical components as well as positive and negative sequence input active powers from the obtained current and voltage signals.

In section $\mathrm{V}$, the generality of the proposed evolutionary based efficiency estimation algorithm is verified based on the experimental results with two squirrel cage induction machines. The accuracy of the experimental results is studied in section VI, to find the magnitude of the probable error caused by the measurement instruments. In section VII, the repeatability of the tests are examined to demonstrate the credibility of the method.

\section{FUnDAMENTALS OF THE IN-SITU EFFICIENCY ESTIMATION ALGORITHM}

In the presence of an unbalanced supply condition in the voltages, the performance of an induction machine can be represented by the positive and negative sequence equivalent circuits as shown in Fig. 1.

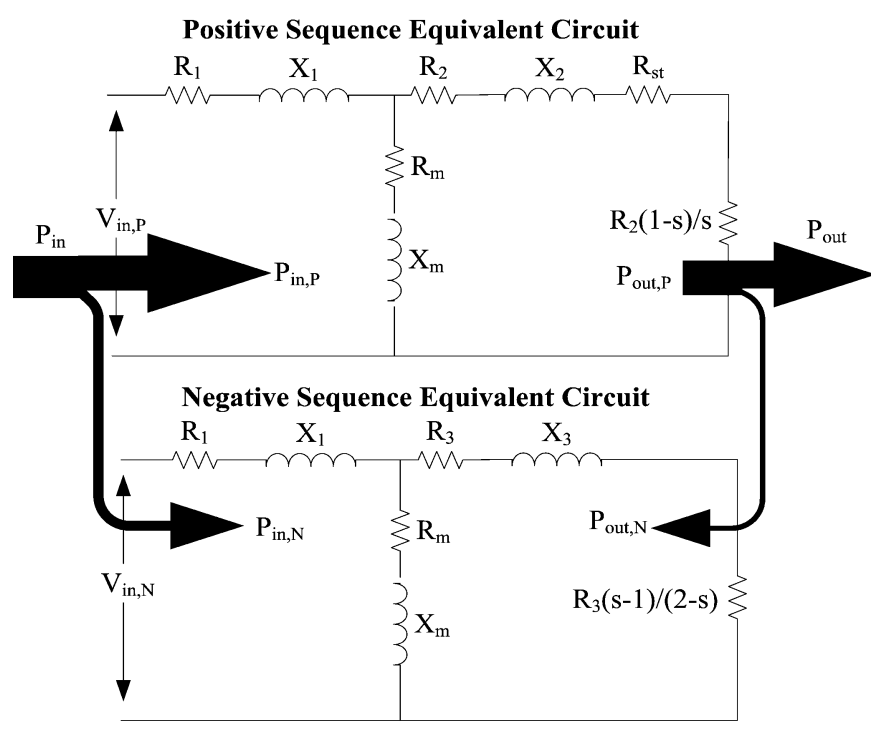

Fig. 1. Positive and negative sequence equivalent circuits of an induction machine [21]

Where

$\mathrm{R}_{1}$ : is the stator resistance.

$\mathrm{X}_{1}$ : is the stator leakage reactance.

$\mathrm{R}_{2}$ : is the rotor positive sequence resistance.

$\mathrm{X}_{2}$ : is the rotor positive sequence leakage reactance.

$\mathrm{R}_{3}$ : is the rotor negative sequence resistance.

$\mathrm{X}_{3}$ : is rotor negative sequence leakage reactance.

$\mathrm{X}_{\mathrm{m}}$ : is mutual reactance of the machine.

$\mathrm{R}_{\mathrm{m}}$ : is representative of the core losses.

$\mathrm{R}_{\mathrm{st}}$ : is representative of the stray load losses defined based on IEEE 112 std. [22].

$\mathrm{s}$ : is the slip of the induction motor.

The efficiency of a machine in the presence of unbalanced supplies can be calculated from (1).

$\eta=\frac{\left|P_{\text {out }, P}\right|-\left|P_{\text {out }, N}\right|-P_{F W}}{\left|P_{\text {in }, P}\right|+\left|P_{\text {in }, N}\right|}$

Where

$\mathrm{P}_{\mathrm{FW}}$ : is the friction and windage losses

$\mathrm{P}_{\mathrm{in}, \mathrm{P}}$ : is the positive sequence input active power

$P_{i n, N}$ : is the negative sequence input active power

$\mathrm{P}_{\text {out, } \mathrm{P}}$ : is the positive sequence output converted power

$\mathrm{P}_{\text {out,N}}$ : is the negative sequence output converted power

The values of the positive and negative sequence input active powers can be obtained non-intrusively with measurement of only two line voltages and currents at each operating point. However, measurement of the mechanical output power, which requires measurement of the torque and the speed of the shaft, is not possible non-intrusively as 
defined here.

Therefore, the positive and negative sequence components of the output power shall be estimated for each operating point. To obtain the speed, the slip of the induction machine at each operating point is estimated non-intrusively based on a method described in section III.

The main problem is to estimate the machine's unknown parameters based on limited measurements. For each operating point there are four known values and 8 unknown parameters (shown in Fig. 1). Since the number of known equations (available data) at one operating point is not sufficient for estimation of all unknown parameters, the data of multiple operating points are used to increase the number of equations and to force the search algorithm to converge to a unique solution.

It is reasonable to assume that the machine works at steady state loading condition (ex. 0.75 of rated load), which allows steady state measurements to be made. This means that the temperature of the machine is stabilized at this loading condition and it remains the same during the short term load variations. This means it is possible to have a set of data with different electrical loading points for the same thermal condition.

The positive sequence parameters of the machine are estimated with help of an evolutionary search algorithm. Knowing the negative sequence input active power $\left(\mathrm{P}_{\mathrm{in,N}}\right)$, knowing the negative sequence voltage magnitude $\left(\mathrm{V}_{\mathrm{in}, \mathrm{N}}\right)$ and the negative sequence input current magnitude $\left(\mathrm{I}_{\mathrm{in}, \mathrm{N}}\right)$, the negative sequence equivalent circuit can be used to calculate the negative sequence rotor currents at each operating point.

To reduce the number of unknown parameters, it is assumed that the value of the cold stator resistance at the ambient temperature (based on preliminary measurements) and the ratio of $\mathrm{X}_{1} / \mathrm{X}_{2}$ is known (based on the design class of the machine which is shown on the nameplate).

Each individual of a generation is made up of 5 parameters as shown in Fig. 2.

\begin{tabular}{|l|l|l|l|l|}
\hline $\mathrm{X}_{2}$ & $\mathrm{R}_{2}$ & $\mathrm{X}_{\mathrm{m}}$ & $\mathrm{R}_{\mathrm{m}}$ & $\mathrm{K}_{\mathrm{th}}$ \\
\hline
\end{tabular}

Fig. 2. One individual of the population.

$\mathrm{K}_{\mathrm{th}}$ is the thermal coefficient of the machine.

The specification of the used evolutionary algorithm is as follows:

- Population number: 250 individuals

- Initial population: Randomly selected in a predefined period

- Recombination: Single arithmetic recombination $P_{c}=0.8$.

- Mutation: Non uniform mutation with a fixed distribution $\mathrm{P}_{\mathrm{m}}=0.2$.

- Reproduction: Tournament based selection combined with elitism (2 fittest old individuals).

A fitness (goal) function inspired from a non linear least square optimization technique is used to find a unique set of solutions (parameters) which has the least square error at all of the operating points as shown in (2).

$$
F=\frac{1}{1+f_{1}^{2}+\sum_{i=1}^{5}\left(f_{2, i}{ }^{2}+f_{3, i}{ }^{2}\right)}
$$

In which $f_{1}$, is the percentage of the error between estimated full load temperature ( $\mathrm{T}_{\text {Rated,Est }}$ ) (using estimated motor parameters as well as nominal voltage and speed values) and the real full load temperature $\left(\mathrm{T}_{\text {Rated }}\right)$ which is known based on the rated temperature rise indicated on the nameplate or the insulation class of the machine as shown in (3).

$$
f_{1}=\frac{\left(T_{\text {Rated }}-T_{\text {Rated }, \text { Est }}\right)}{T_{\text {Rated }}} \times 100
$$

$f_{2, \mathrm{i}}$ is the percentage of the positive sequence input current estimation error at operating point " $\mathrm{i}$ " as defined in (4).

$f_{2, i}=\frac{\left(I_{i n, P, i}-I_{i n, P, i, E s t}\right)}{I_{i n, P, i}} \times 100$

$f_{3, \mathrm{i}}$ is the percentage of the positive sequence input active power estimation error at operating point " $\mathrm{i}$ " as presented in (5).

$f_{3, i}=\frac{\left(P_{i n, P, i}-P_{i n, P, i, E s t}\right)}{P_{i n, P, i}} \times 100$

The overall flowchart of the proposed method is presented in Fig. 3.

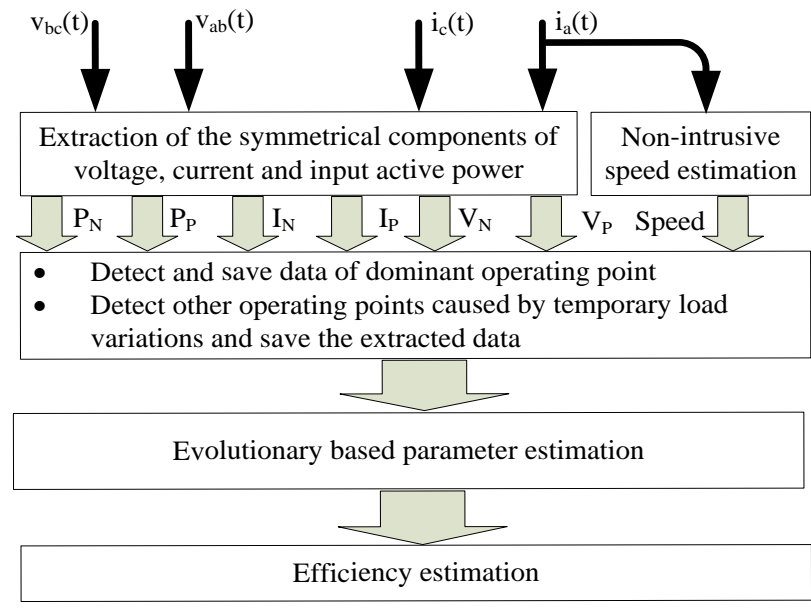

Fig. 3. Flow chart of the proposed efficiency estimation technique

\section{NON-INTRUSIVE SPEED DETECTION TECHNIQUE}

A machine current signature analysis (MCSA) based speed detection technique that uses rotor eccentricity harmonics is proposed here. Based on [23], the eccentricity of the rotor (due to the oval shape of the rotor) creates speed dependent current harmonics. The largest (in magnitude) speed dependent current harmonic has a frequency that can be found from (6).

$F=\left(1 \pm \frac{1-s}{P}\right) \cdot F_{s}$

" $F_{\mathrm{s}}$ " is the supply frequency, "s" is the slip and "P" is the pole pair number. The speed dependent current harmonics are extremely small in comparison to the fundamental component of the current. Since the frequencies of these components are close to the fundamental frequency, they will be masked by 
the main component of the current and that makes the detection process complicated. To avoid this problem, a specific non linear adaptive algorithm is presented to extract the fundamental component of the current from its signal.

After extraction of the main component, the spectral analysis of the residual (remaining) signal is used to detect the speed dependent current harmonics.

\section{A. Mathematics of the Non Linear Adaptive Algorithm}

Consider a desired sinusoidal signal $I_{f}(t)=A(t) \cdot \sin \varphi(t)$

(fundamental component of the current in this case) combined with some other sinusoidal components as well as noise as shown in (7) and (8).

$$
\begin{aligned}
& I(t)=\sum_{i=0}^{\infty} A_{i}(t) \cdot \sin \varphi_{i}(t)+n(t) \\
& \varphi_{i}(t)=\int^{t} \omega_{i}(t) d t+\alpha_{i}(t)
\end{aligned}
$$

$A(t)$ is the signal's magnitude, $\omega(t)$ is the frequency, $\alpha(t)$ is the phase angle and $n(t)$ is the noise component. As discussed in detail in [20], the formulation of the algorithm is inspired from the gradient descent method and it tracks the desired sinusoidal component of the signal by minimizing the least square of the error function as defined in (9).

$e(t)=I(t)-A(t) \cdot \sin \varphi(t)$

The governing equations of the non linear algorithm are presented in (10) to (12).

$$
\begin{aligned}
& \frac{d A(t)}{d t}=m_{1} \cdot e(t) \cdot \sin \varphi(t) \\
& \frac{d \omega(t)}{d t}=m_{2} \cdot e(t) \cdot A(t) \cdot \cos \varphi(t) \\
& \frac{d \varphi(t)}{d t}=\omega(t)+m_{3} \cdot \frac{d \omega(t)}{d t}
\end{aligned}
$$

The block diagram of this algorithm is shown in Fig. 4.

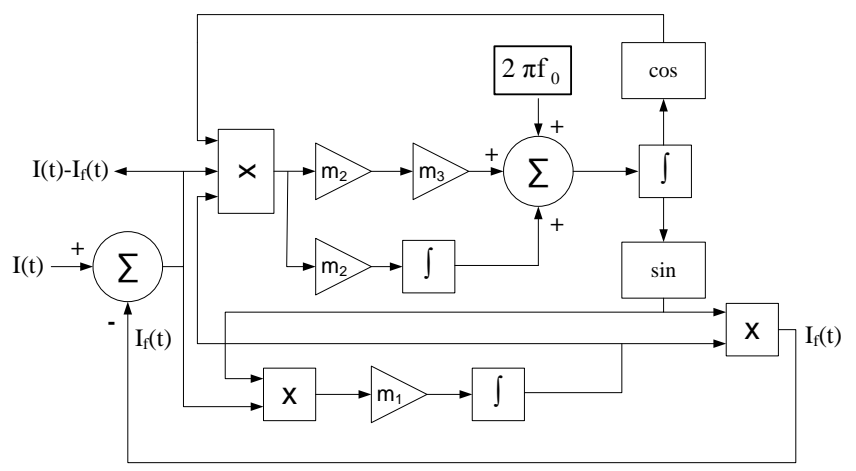

Fig. 4. Block diagram of the proposed non linear algorithm

The convergence speed and the steady state error of the algorithm are dependent on the values of the constants $\mathrm{m}_{1}, \mathrm{~m}_{2}$ and $\mathrm{m}_{3}$. The value of the constant $\mathrm{m}_{1}$ affects the speed of tracking of the changes in the magnitude of the desired component while $\mathrm{m}_{2}$ and $\mathrm{m}_{3}$ affect the frequency and phase tracking capabilities. The value of these parameters shall be chosen based on a compromise between the steady state error and the speed of convergence. In [20] the stability of this algorithm is proven mathematically and more details are provided about the characteristics of the algorithm and the conditions of the constants. This algorithm acts as an adaptive notch filter in the sense that it passes a desired sinusoidal component and it rejects all other components as well as superimposed noise. This algorithm is capable of extracting the main component of a signal in the presence of other components as well as noise even if there are changes in the frequency or magnitude of the main component.

\section{B. Comparison of the estimated vs. measured speeds}

Fig. 5, shows the measured input current of one of the phases of the tested $3 \mathrm{hp}$ induction motor (at full load condition under unbalanced supply) as well as the residual current after extraction of the main component.

The nameplate data of the tested machine is provided in Table I.

TABLE I

NAMEPLATE DATA OF 3 HP INDUCTION MACHINE

\begin{tabular}{cccc}
\hline \hline $\mathrm{f}$ & $60 \mathrm{~Hz}$ & Design class & $\mathrm{B}$ \\
$\mathrm{V}_{\mathrm{LL}}$ & 208 & Insulation class & $\mathrm{B}$ \\
$\mathrm{I}$ & 10.3 & Nominal speed & 1740 \\
Connection & $\mathrm{Y}$ & Poles & 4 \\
\hline
\end{tabular}

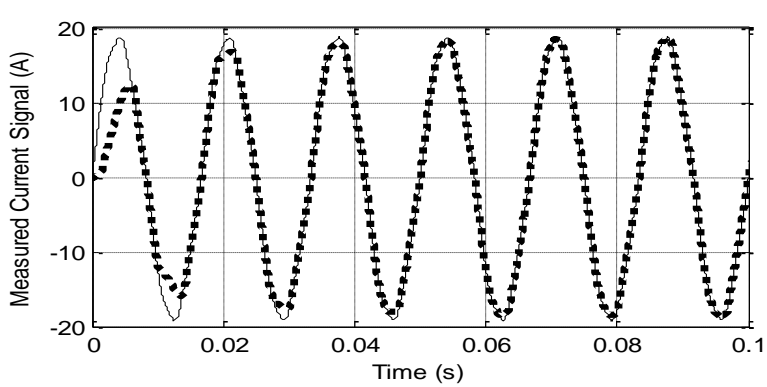

$$
\begin{aligned}
& \text {-1-1-- Tracked fundamental component } \\
& \text { Measured current }
\end{aligned}
$$

(a)

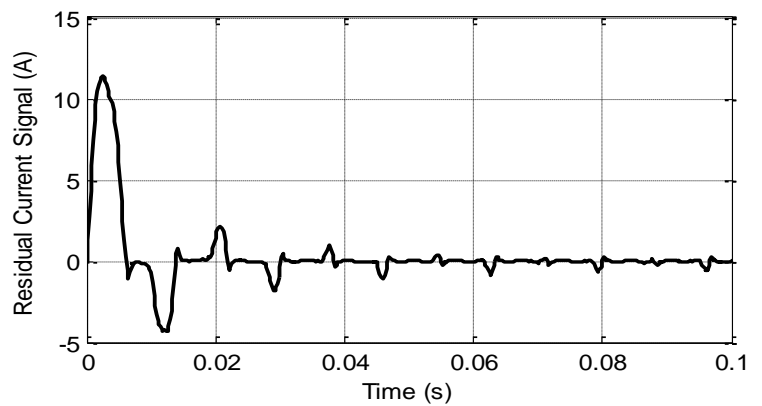

(b)

Fig. 5 a) Measured current signal and the tracked fundamental component b) residual current signal

The harmonic spectra of the current signal before and after extraction of the main component are shown in Fig. 6. The smaller harmonics are detectable after extraction of the main component. Based on the theory of induction machines one can expect to have the speed value somewhere between the synchronous speed (1800 rpm in this case) and the rated speed (which is $1740 \mathrm{rpm}$ for the machine). However, considering 
the possibility of working under overload conditions, the lowest possible speed is considered around $1700 \mathrm{rpm}$.

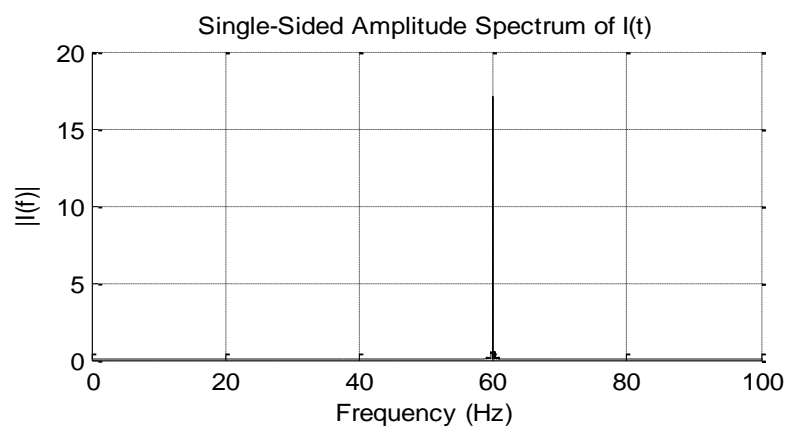

(a)

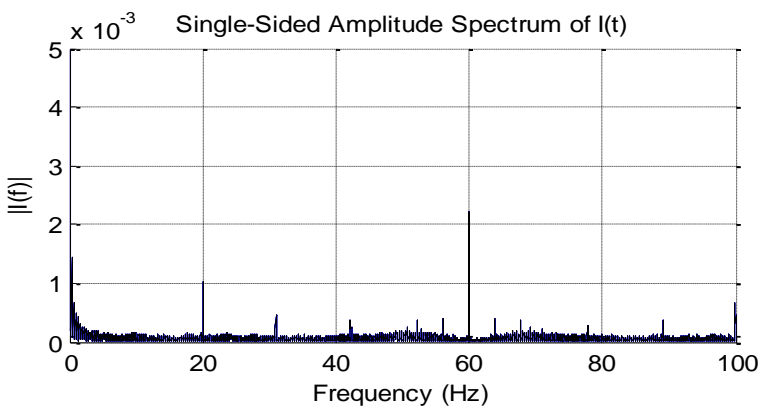

(b)

Fig. 6 a) Harmonic spectrum of the measured current signal b) harmonic spectrum of the residual signal

Considering the number of the pole pairs equal to 2 , supply frequency of $60 \mathrm{~Hz}$ and slip range from 0 to 0.055 (1700 rpm), it is anticipated that a speed dependent current harmonic will be somewhere between $30 \mathrm{~Hz}$ and $31.67 \mathrm{~Hz}$.

The harmonic spectra of the residual currents of the tested 3 hp machine are shown in Fig. 7 at two loading points.

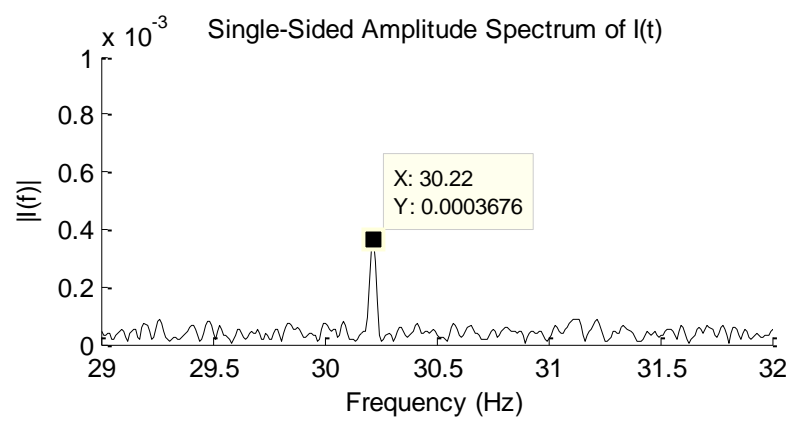

(a)

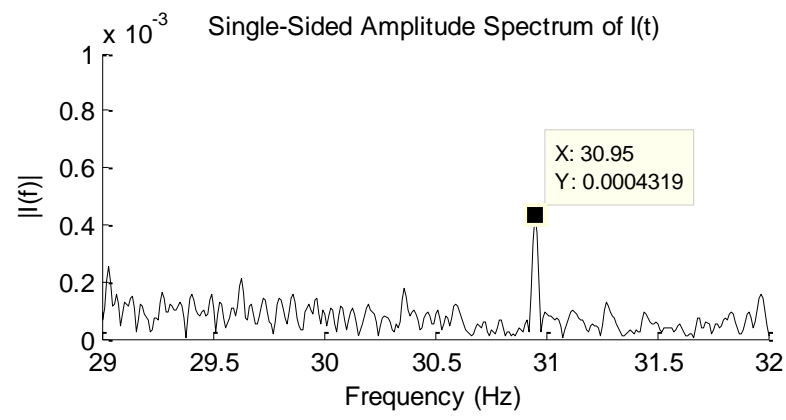

(b)

Fig. 7. a) Harmonic spectrum of the residual signal at a) around $25 \%$ of rated load b) around rated load
Based on (6) the frequency of $30.22 \mathrm{~Hz}$ is translated to $1786.0 \mathrm{rpm}$ and $30.95 \mathrm{~Hz}$ to $1742.3 \mathrm{rpm}$. The comparison of the estimated speeds and the measured ones with tachometer results are presented in Table II for different loading conditions under about $5 \%$ of voltage unbalance factor and in the thermal condition of 0.75 of the rated load. The estimation was based on 60 seconds of data acquisition with $5 \mathrm{kHz}$ sampling rate.

TABLE II

MEASURED VS. ESTIMATED SPEEDS FOR THE 3HP MOTOR

\begin{tabular}{cccc}
\hline \hline \% of rated load & $\begin{array}{c}\text { Measured } \\
(\mathrm{rpm})\end{array}$ & $\begin{array}{c}\text { Estimated } \\
(\mathrm{rpm})\end{array}$ & Error $(\%)$ \\
\hline 25 & 1785 & 1786.0 & 0.06 \\
50 & 1772 & 1773.1 & 0.06 \\
75 & 1759 & 1760.0 & 0.06 \\
85 & 1751 & 1751.9 & 0.05 \\
100 & 1741 & 1742.3 & 0.07 \\
\hline \hline
\end{tabular}

The same test is performed with a $10 \mathrm{hp}$ premium efficiency induction machine to check the generality of the method. The nameplate of the machine is shown in Table III. The estimated speeds are compared with the measured values as shown in Table IV.

TABLE III

NAMEPLATE DATA OF 10 HP INDUCTION MACHINE

\begin{tabular}{cccc}
\hline \hline $\mathrm{f}$ & $50 \mathrm{~Hz}$ & Design class & $\mathrm{B}$ \\
$\mathrm{V}_{\mathrm{LL}}$ & 380 & Insulation class & $\mathrm{F}$ \\
$\mathrm{I}$ & 14.4 & Nominal speed & 1460 \\
Connection & $\Delta$ & Poles & 4 \\
\hline
\end{tabular}

TABLE IV

MEASURED vs. ESTIMATED SPEEDS FOR THE 10HP MOTOR

\begin{tabular}{cccc}
\hline \hline \% of rated load & $\begin{array}{c}\text { Measured } \\
(\mathrm{rpm})\end{array}$ & $\begin{array}{c}\text { Estimated } \\
(\mathrm{rpm})\end{array}$ & Error $(\%)$ \\
\hline 25 & 1494 & 1493.9 & -0.01 \\
50 & 1486.2 & 1486.5 & 0.02 \\
75 & 1481.9 & 1482.1 & 0.01 \\
85 & 1474.8 & 1474.9 & 0.01 \\
100 & 1466.7 & 1467.0 & 0.02 \\
\hline \hline
\end{tabular}

As it can be seen, the results of this technique are in very good accordance with the tachometer measurements.

\section{EXTRACTION OF THE SYMMETRICAL COMPONENTS}

An unbalanced power supply creates unbalanced currents in the machine. The unbalanced currents produce negative sequence and positive sequence fluxes, and they result in positive sequence and negative sequence torque components. The magnitude and the phase of the positive sequence and negative sequence components of the voltage and current signals are required for extraction of the positive and negative sequence components of the input active power. All these extracted components are used in the developed algorithm to estimate the parameters and the efficiency of the induction machine as shown in Fig. 3. 
The proposed non linear algorithm can be used to track the fundamental component and to extract the phasor information (magnitude and phase shift). The algorithm is capable of dealing with frequency fluctuations while estimating the phasor quantities.

Fig. 8 shows the block diagram of the proposed algorithm which is based on the combination of the proposed non linear adaptive algorithm and the Fortescue transformation matrix that is shown in (13). Based on this method the phase and the magnitude of the symmetrical components can be directly extracted from two line voltage and current signals.

$\left[\begin{array}{c}I_{0} \\ I_{P} \\ I_{N}\end{array}\right]=\frac{1}{3}\left[\begin{array}{ccc}1 & 1 & 1 \\ 1 & K & K^{2} \\ 1 & K^{2} & K\end{array}\right]\left[\begin{array}{c}I_{a} \\ I_{b} \\ I_{c}\end{array}\right]$

In which $K=e^{j \frac{2 \pi}{3}}$

\section{$\mathrm{I}_{\mathrm{a}}, \mathrm{I}_{\mathrm{b}}, \mathrm{I}_{\mathrm{c}}$ : Three phase phasor quantities}

$\mathrm{I}_{0}, \mathrm{I}_{\mathrm{P}}, \mathrm{I}_{\mathrm{N}}:$ Zero, positive and negative sequence phasor quantities

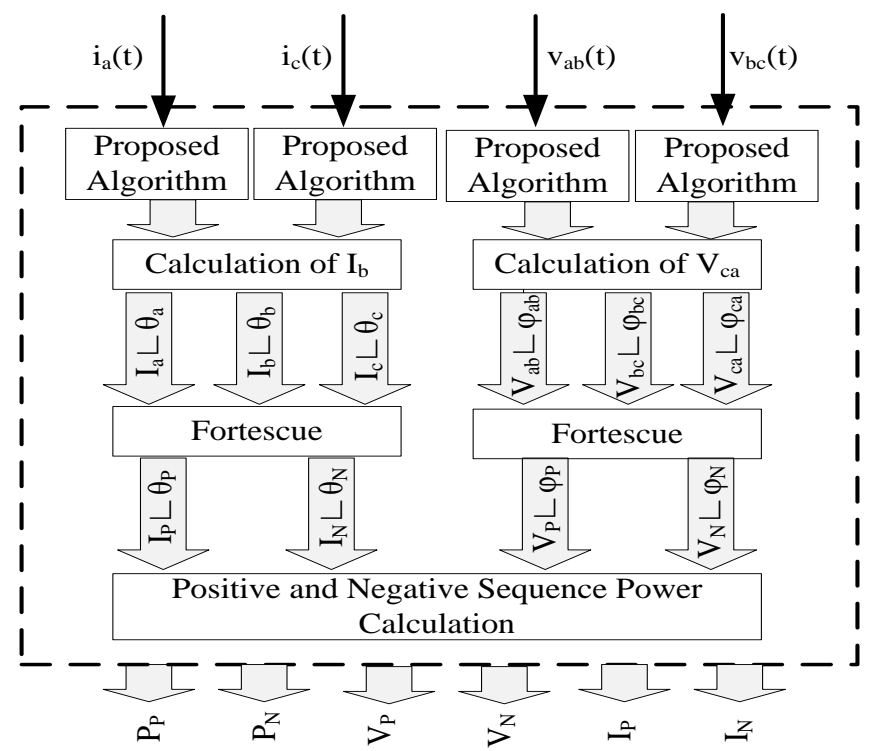

Fig. 8. Block diagram of the proposed online symmetrical component extraction method

The recorded voltage and current signals of the tested $3 \mathrm{hp}$ and $10 \mathrm{hp}$ induction machines at full load condition with about $5 \%$ voltage unbalance factor (VUF) in case of $3 \mathrm{hp}$ and $6 \%$ VUF in case of $10 \mathrm{hp}$ motor are shown as an example in Fig. 9 and Fig. 10 respectively. The extracted components of the signals as well as the estimated positive and negative sequence components of the input active power are shown for the case of the 3hp motor in Fig. 11. The proposed algorithm can be used to extract all the required data that is used in the efficiency estimation process.

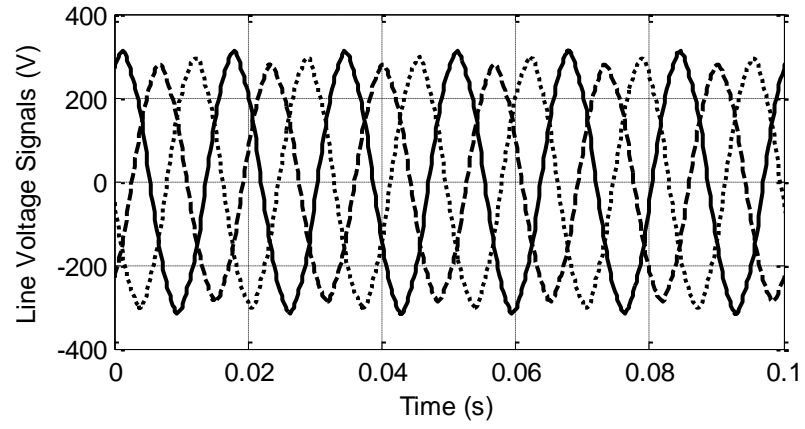

(a)

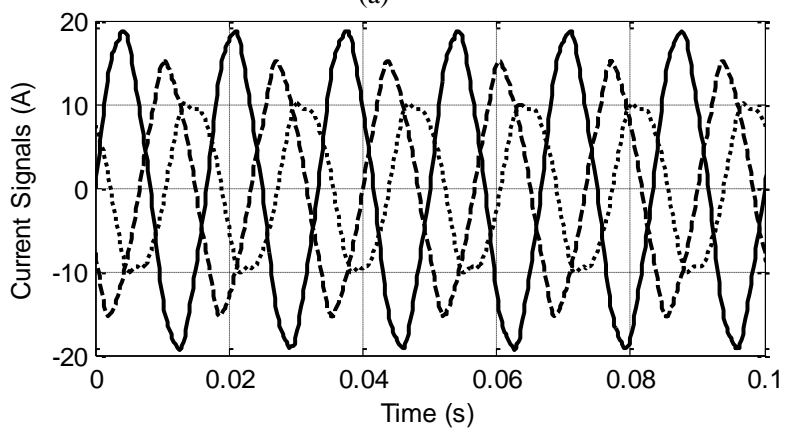

(b)

Fig. 9. Recorded signals of 3HP induction motor a) three phase voltage b) three phase current under 5\% VUF and rated load condition

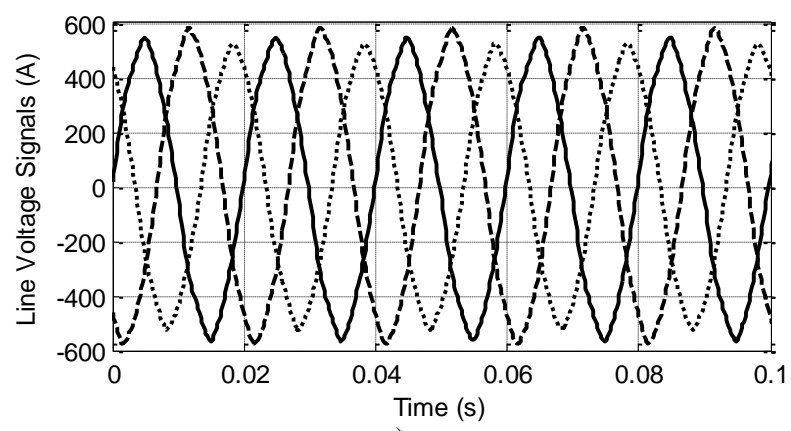

a)

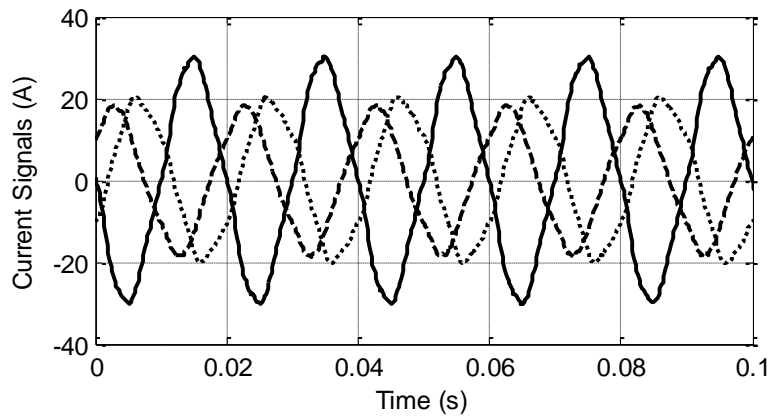

b)

Fig. 10. Recorded signals of $10 \mathrm{HP}$ induction motor a) three phase voltage b) three phase current under 6\% VUF and rated load condition

The symmetrical components of the voltage, current and input active power are extracted for the two tested machines from the measured current and voltage signals, in the dominant loading condition as well as four other short-term loading points as shown in Table $\mathrm{V}$ and Table VI. 


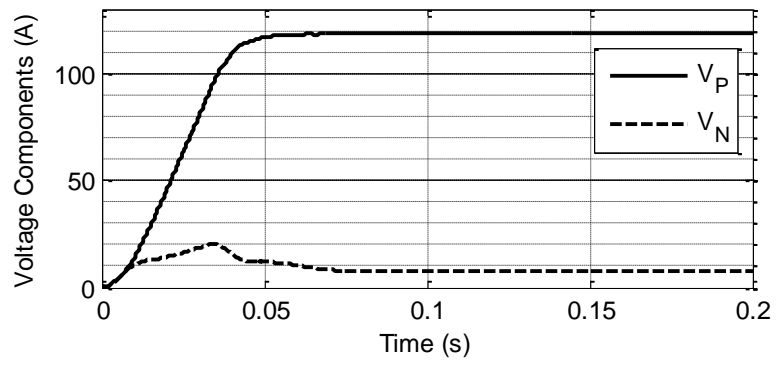

(a)

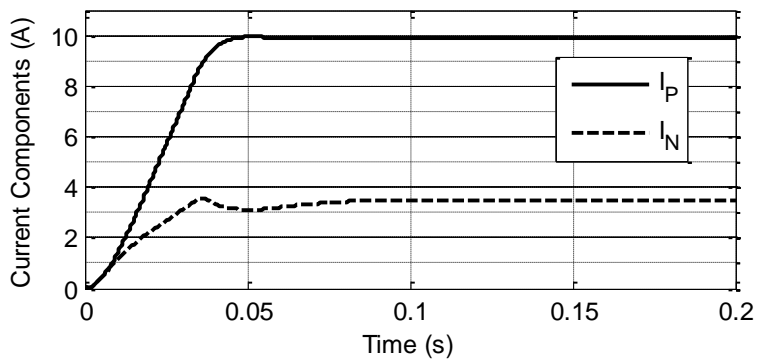

(b)

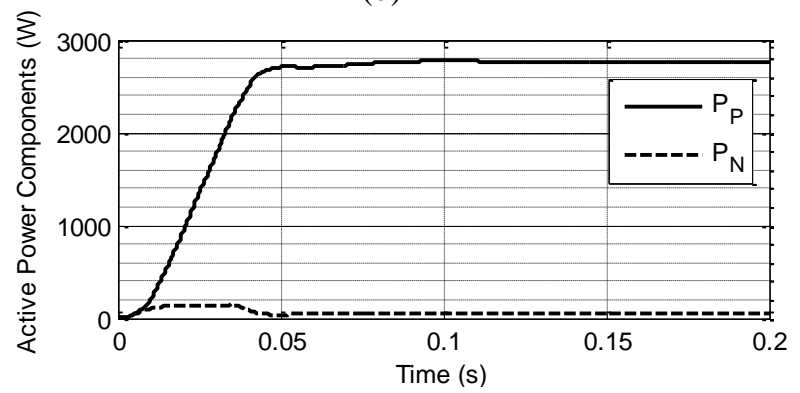

(c)

Fig. 11. Positive and negative sequence components of a) input voltage b) input current c) input active power under 5\% VUF and rated load condition

This data is used in the proposed evolutionary based efficiency estimation algorithm to estimate the efficiency of the machine under different loading conditions as discussed in section II and the results are shown in the following section.

TABLE V

FIVE DifFERENT OPERATING POINTS OF 3HP MACHINE WiTH AROUND 5\% VOLTAGE UNBALANCE FACTOR

\begin{tabular}{cccccc}
\hline \multicolumn{5}{c}{ VOLTAGE UNBALANCE FACTOR } \\
$\begin{array}{c}\text { rated } \\
\text { load }\end{array}$ & $\mathbf{2 5}$ & $\mathbf{5 0}$ & $\mathbf{7 5}$ & $\mathbf{8 5}$ & $\mathbf{1 0 0}$ \\
\hline $\mathrm{V}_{\mathrm{in}, \mathrm{P}}$ & 120.30 & 119.82 & 119.25 & 118.58 & 118.53 \\
$\mathrm{~V}_{\mathrm{in}, \mathrm{N}}$ & 7.47 & 7.39 & 7.24 & 7.32 & 7.25 \\
$\mathrm{I}_{\mathrm{in}, \mathrm{P}}$ & 6.26 & 7.00 & 8.21 & 8.81 & 9.85 \\
$\mathrm{I}_{\mathrm{in}, \mathrm{N}}$ & 3.41 & 3.43 & 3.43 & 3.47 & 3.46 \\
$\mathrm{P}_{\mathrm{in}, \mathrm{P}}$ & 872.94 & 1468.32 & 2087.04 & 2359.50 & 2765.63 \\
$\mathrm{P}_{\mathrm{in}, \mathrm{N}}$ & 47.47 & 48.90 & 49.48 & 51.63 & 51.86 \\
$\mathrm{Speed}$ & 1786.0 & 1773.1 & 1760.0 & 1751.9 & 1742.3 \\
\hline
\end{tabular}

TABLE VI

Five DifFERENT OPERATING POINTS OF 10HP MACHINE With AROUND 6\% VOLTAGE UNBALANCE FACTOR

\begin{tabular}{cccccc}
\hline \hline $\begin{array}{c}\text { \% of } \\
\text { rated } \\
\text { load }\end{array}$ & $\mathbf{2 5}$ & $\mathbf{5 0}$ & $\mathbf{7 5}$ & $\mathbf{8 5}$ & $\mathbf{1 0 0}$ \\
\hline $\mathrm{V}_{\mathrm{in}, \mathrm{P}}$ & 379.78 & 382.04 & 380.35 & 378.80 & 378.12 \\
$\mathrm{~V}_{\mathrm{in}, \mathrm{N}}$ & 22.68 & 23.30 & 22.54 & 22.57 & 22.31 \\
$\mathrm{I}_{\mathrm{in}, \mathrm{P}}$ & 3.52 & 4.86 & 6.46 & 7.31 & 8.50 \\
$\mathrm{I}_{\mathrm{in}, \mathrm{N}}$ & 2.26 & 2.91 & 3.12 & 3.20 & 3.25 \\
$\mathrm{P}_{\mathrm{in}, \mathrm{P}}$ & 2463.42 & 4392.26 & 6347.52 & 7311.23 & 8630.89 \\
$\mathrm{P}_{\mathrm{in}, \mathrm{N}}$ & 54.06 & 87.60 & 95.71 & 101.39 & 103.32 \\
Speed & 1493.9 & 1486.5 & 1482.1 & 1474.9 & 1467.0 \\
\hline
\end{tabular}

\section{Testing OF The Proposed Method}

In this section the proposed algorithm is used to estimate the efficiency of a $3 \mathrm{hp}$ and a $10 \mathrm{hp}$ squirrel cage induction motors with nameplates as shown in the Table I and Table III.

An experimental setup with the schematic as shown in Fig. 12 was used for this test.

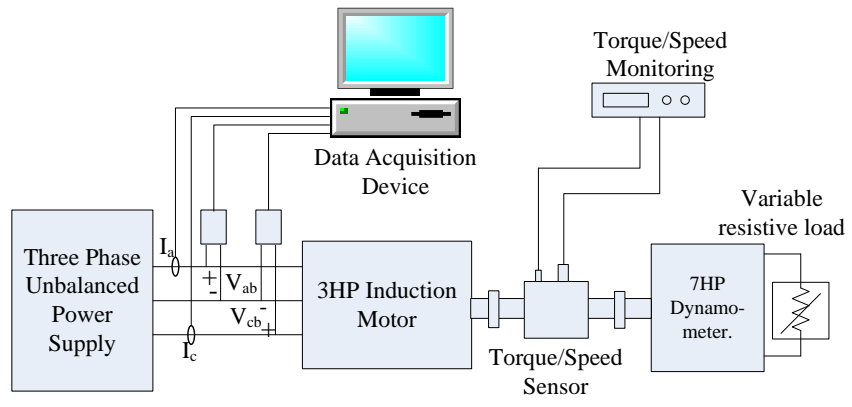

Fig. 12. Schematic of the test setup used for this experiment.

Fig. 13 shows the experimental setup of the $3 \mathrm{hp}$ motor in the laboratory specifically for in-situ efficiency estimation tests.

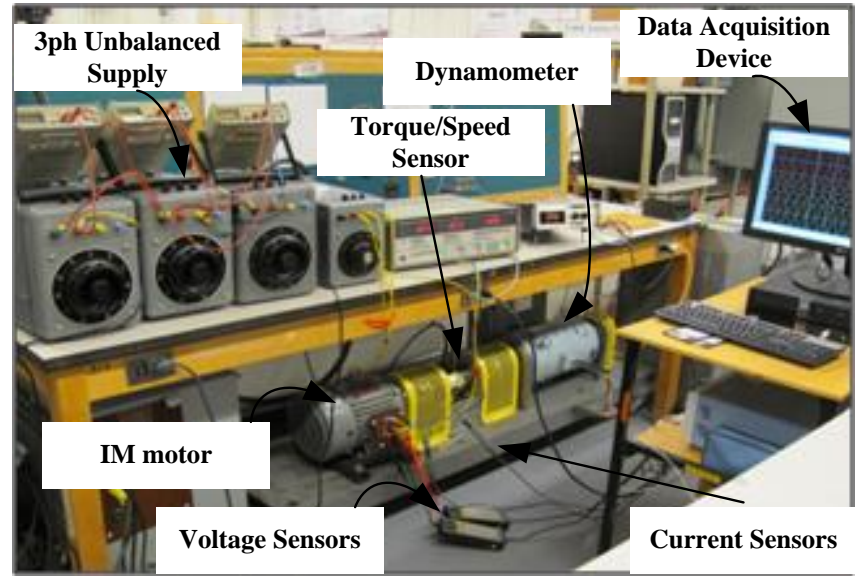

Fig. 13. The test setup of the $3 \mathrm{hp}$ induction machine

As can be seen from Figs. 12 and 13, the induction motor was coupled to a dynamometer. Thus, it was possible to impose different torque levels on the shaft of the induction motor. The three phase unbalanced power supply was produced with three single phase variacs as well as a step-up 
transformer. The extracted data of the five operating points were imported into the developed floating point evolutionary efficiency estimation algorithm as a set of input data.

The trend of the improvement of the fitness function (after each generation) is illustrated in Figs. 14 and 15 for the 3hp and the $10 \mathrm{hp}$ machines respectively. The value of the average error between estimated and measured positive sequence currents and powers at different operating points is around $0.74 \%$, after the convergence of the algorithm in the case of the $3 \mathrm{hp}$ machine and $0.76 \%$ in the case of the $10 \mathrm{hp}$ machine.

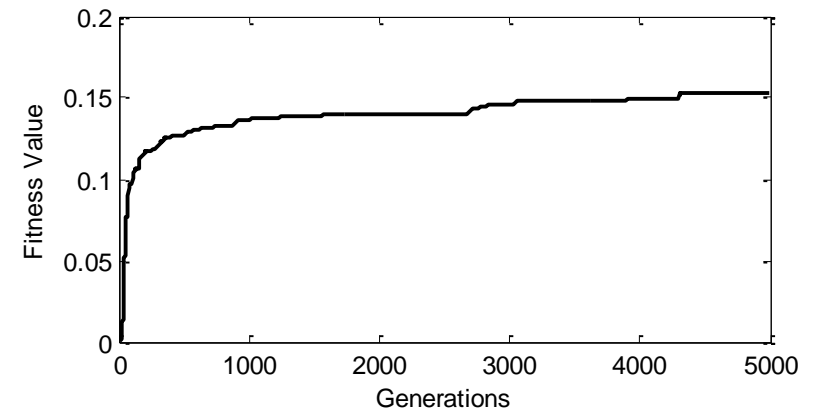

Fig. 14. Trend of the improvement of the fitness value for the $3 \mathrm{hp}$ machine.

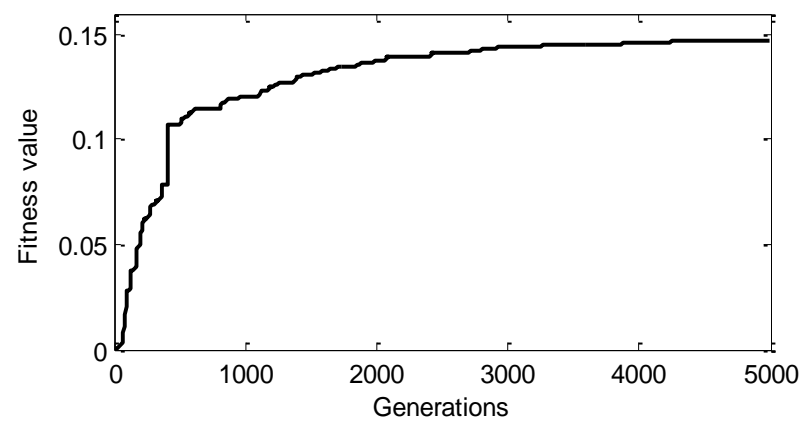

Fig.15. Trend of the improvement of the fitness value for the 10hp machine.

The efficiency of the machine is calculated after estimation of the positive and negative sequence components. The results are compared with the direct measured efficiency values (with the help of the installed torque/speed sensor) as tabulated in Table VII and Table VIII for the 3hp and the $10 \mathrm{hp}$ machines and as shown in Figs. 16 and 17 respectively.

TABLE VII

ESTIMATED EFFICIENCIES VS. MEASURED EFFICIENCIES FOR THE 3 HP MACHINE

\begin{tabular}{cccccc}
\hline \hline \% of rated load & $\mathbf{2 5}$ & $\mathbf{5 0}$ & $\mathbf{7 5}$ & $\mathbf{8 5}$ & $\mathbf{1 0 0}$ \\
\hline Measured efficiencies & 59.17 & 72.57 & 77.43 & 77.64 & 78.23 \\
Estimated efficiencies & 63.42 & 74.82 & 78.55 & 79.17 & 79.42 \\
Error (\%) & 4.25 & 2.25 & 1.12 & 1.53 & 1.19 \\
\hline
\end{tabular}

TABLE VIII

ESTIMATED EFFICIENCIES VS. MEASURED EFFICIENCIES FOR THE $10 \mathrm{HP}$ MACHINE

\begin{tabular}{cccccc}
\hline \hline \% of rated load & $\mathbf{2 5}$ & $\mathbf{5 0}$ & $\mathbf{7 5}$ & $\mathbf{8 5}$ & $\mathbf{1 0 0}$ \\
\hline Measured efficiencies & 78.55 & 84.70 & 86.94 & 86.51 & 86.22 \\
Estimated efficiencies & 86.45 & 88.42 & 88.31 & 87.74 & 86.84 \\
Error (\%) & 7.90 & 3.73 & 1.37 & 1.23 & 0.62 \\
\hline
\end{tabular}

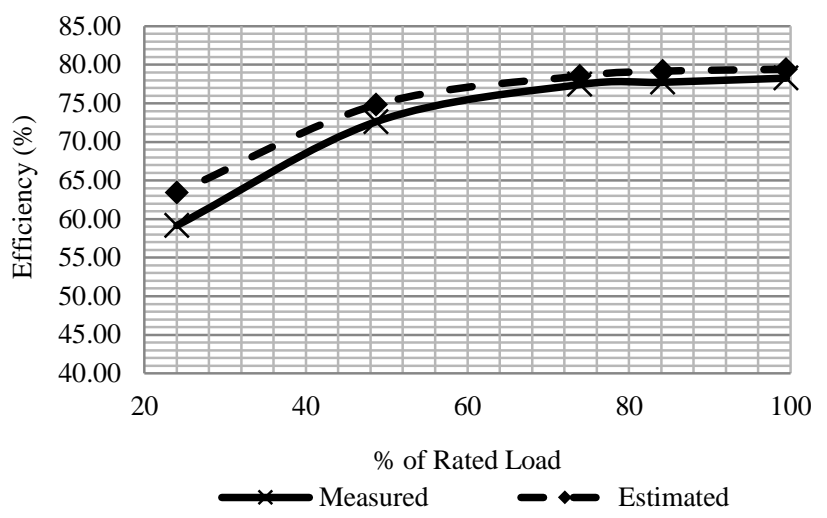

Fig. 16. Comparison of the estimated and measured efficiencies for the tested $3 \mathrm{hp}$ machine with $5 \%$ voltage unbalance factor

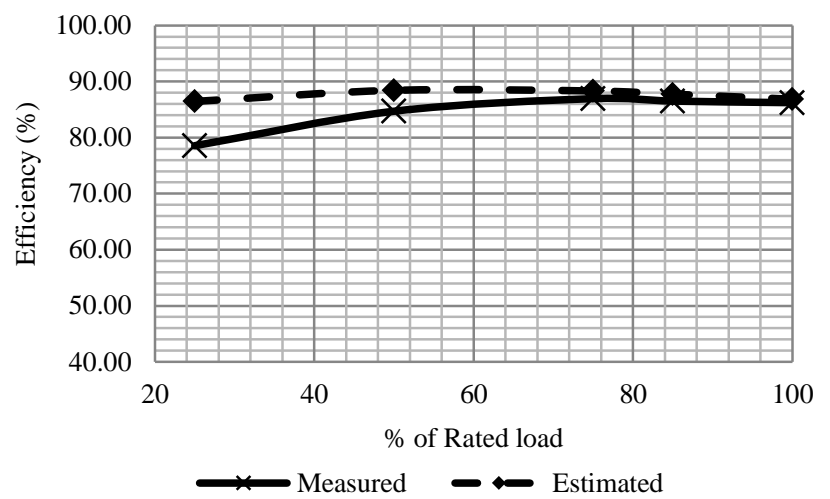

Fig. 17. Comparison of the estimated and measured efficiencies for the tested $10 \mathrm{hp}$ machine with $6 \%$ voltage unbalance factor

The experimental result proves the effectiveness, feasibility and generality of the developed in-situ efficiency estimation technique.

\section{MEASUREMENT ERROR ANALYSIS}

In the previous sections, a comparison of the estimated efficiencies with the measured ones was used to validate the effectiveness of the proposed in-situ efficiency estimation algorithm. However, the accuracy of the measured values must be guaranteed in order to be able to use them as a reference for comparison.

In a typical experiment, three types of error may exist. The first one is the methodological error, the second one is the human error and the third one is caused by the instrumental error. Instrumental error is the most dominant type of the error for the efficiency estimation problem and it can be calculated with three common error evaluation techniques that are presented below [24-25]:

1-Maximum error estimation (MEE)

2- Worst case error estimation (WCEE)

3- Realistic error estimation (REE)

The Maximum error estimation technique gives the maximum possible error and it is defined with the following equation. 
$\varepsilon_{\eta}=\max \left|\frac{1 \pm \varepsilon_{\text {Pout }}}{1 \pm \varepsilon_{\text {Pin }}}\right|-1=\max \left|\frac{\left(1 \pm \varepsilon_{T}\right) \cdot\left(1 \pm \varepsilon_{S}\right)}{\left(1 \pm \varepsilon_{V}\right) \cdot\left(1 \pm \varepsilon_{I}\right)}\right|-1$

Where

$\varepsilon_{\eta}:$ Relative error of the measured efficiency

$\varepsilon_{\text {Pout }}:$ Relative error of the measured output power

$\varepsilon_{\text {Pin }}:$ Relative error of the measured input power

$\varepsilon_{T}:$ Relative error of the measured torque

$\varepsilon_{S}:$ Relative error of the measured speed

$\varepsilon_{V}:$ Relative error of the measured voltage

$\varepsilon_{I}:$ Relative error of the measured current

The relative error for a parameter is defined as the ratio of the absolute error to the true value of the parameter.

The relative errors of the instruments, used in the efficiency measurement of the 10hp machine, are as follows:

- Torque sensor: $\pm 0.2 \%$

- Speed sensor: $\pm 0.05 \%$

- Voltage sensors: $\pm 0.2 \%$

- Current sensors: $\pm 0.2 \%$

Using the provided data on the accuracy of the used instruments and equation (14), the maximum possible error in efficiency measurement can be calculated as in (15).

$\varepsilon_{\eta}=\max \left|\frac{(1 \pm 0.2 \%) \cdot(1 \pm 0.05 \%)}{(1 \pm 0.2 \%) \cdot(1 \pm 0.2 \%)}\right|-1= \pm 0.65 \%$

This is the maximum value of the error that can exist in the measured efficiency values. However, it is unrealistic to have all the errors happening in a way that leads to the calculated maximum error.

Worst case error estimation is another way of handling the error calculation problem. In this method the effect of each error source on the measured component (efficiency in this case) is handled separately and its influence is considered with an influence coefficient as shown in (16) [24].

$\varepsilon_{\eta}=\sum I_{I} \cdot \varepsilon_{I}+I_{V} \cdot \varepsilon_{V}+I_{T} \cdot \varepsilon_{T}+I_{S} \cdot \varepsilon_{S}$

Where

$I_{I}:$ is the influence coefficient of the current

$I_{V}$ : is the influence coefficient of the voltage

$I_{T}$ : is the influence coefficient of the torque

$I_{S}:$ is the influence coefficient of the speed

The value of the influence coefficient for each parameter is found based on a perturbation method where the relative deviation of the output (efficiency) parameter is found for a known perturbation in an input parameter (e.g. current) as shown in (17) for the current [24].

$$
I_{I}=\frac{\varepsilon_{\eta}}{\varepsilon_{I}}
$$

As it is shown in [24] and [25] the influence coefficient of all the parameters in (16) are almost equal to 1 for direct efficiency measurement technique. This means that the error of each instrument has the same influence on the final error of the measured efficiency. Therefore the worst case error for efficiency measurement with direct method will be as follows: $\varepsilon_{\eta}=\sum 1 .( \pm 0.2 \%)+1 .( \pm 0.2 \%)+1 .( \pm 0.2 \%)+$
$+1 .( \pm 0.05 \%)= \pm 0.65 \%$

As it can be seen the WCE method gives almost the same result as the MEE method. This is due to the similar nature of both methods which assume a simultaneous existence of maximum possible errors in all measured parameters.

To have a more realistic value of the error, the REE method should be used. With the assumption of the uniformly distributed error for each parameter the relative distribution of the output can be found based on (19) [24].

$\varepsilon_{\eta}=\sqrt{\sum\left(I_{I} \cdot \varepsilon_{I}\right)^{2}+\left(I_{V} \cdot \varepsilon_{V}\right)^{2}+\left(I_{T} \cdot \varepsilon_{T}\right)^{2}+\left(I_{S} \cdot \varepsilon_{S}\right)^{2}}$

Using the same influence coefficients, the error of the measurement based on REE method is found as shown in (20).

$$
\begin{aligned}
& \varepsilon_{\eta}=\sqrt{\sum(1 . \pm 0.2 \%)^{2}+(1 . \pm 0.2 \%)^{2}+} \\
& \overline{+(1 . \pm 0.2 \%)^{2}+(1 . \pm 0.05 \%)^{2}}= \pm 0.35 \%
\end{aligned}
$$

Based on the achieved results it can be assured that the measurements were done within an acceptable error range.

\section{REPEATABILITY OF THE RESULTS}

In order to guarantee the consistency of the results the test with $3 \mathrm{hp}$ machine is repeated three times and the results are compared as shown in Fig. 18 and 19.

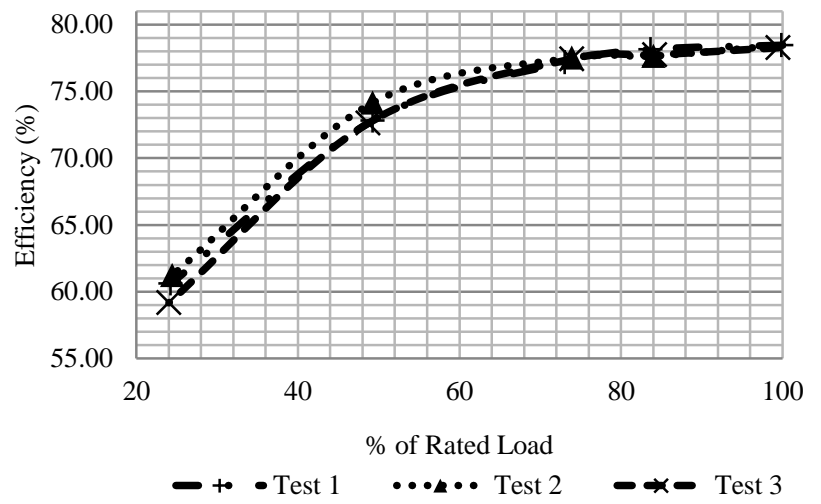

Fig. 18. Repeatability of the measured efficiencies of the $3 \mathrm{hp}$ machine

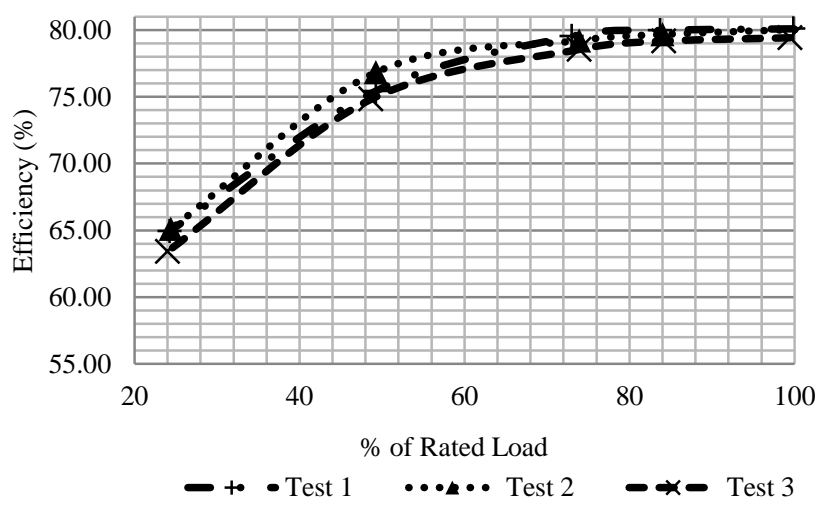

Fig. 19. Repeatability of the estimated efficiencies of the $3 \mathrm{hp}$ machine

As can be seen, the consistency of the achieved results proves the reliability of the proposed method. 


\section{CONCLUSIONS}

In-situ efficiency estimation is a challenging area of electrical machine research work where the lowest level of intrusion and the highest possible accuracy is required. A new algorithm is proposed for machines working with unbalanced supplies and a non intrusive speed estimation technique is developed for efficiency estimation process. The experimental results based on two different machines prove the effectiveness and generality of the proposed technique. The measurement error analysis as well as the results of the repeatability tests further validates the method.

\section{ACKNOWLEDGMENT}

The authors acknowledge the support of the Natural Sciences \& Engineering Research Council of Canada and Hydro-Québec for this work.

\section{REFERENCES}

[1] P. Pillay, K. A. Fendley, "The contribution of energy efficient motors to demand and energy savings in the petrochemical industry," IEEE Trans. Power Systems, vol.10, pp.1085-1093, May 1995.

[2] H.R.776, Energy Policy Act of 1992, sec. 122. "Energy conservation requirements for certain commercial and industrial equipment.energy conservation standards for high-intensity discharge lamps, distribution transformers, and small electric motors" [online], Available: http://thomas.loc.gov

[3] U. S. DOE Energy Efficiency and Renewable Energy (EERE), DOE Industry Tools. DOE Motor Master+ Website, [Online], Available: http://www1 .eere.energy.gov/industry/bestpractices/software.html

[4] Ching-Yin Lee, Bin-Kwie Chen, Wei-Jen Lee, Yen-Feng Hsu, "Effects of various unbalanced voltages on the operation performance of an induction motor under the same voltage unbalance factor condition," in Proc. IEEE Technical Conf. on Industrial and Commercial Power Systems, 1997, pp.51-59.

[5] P. Pillay, P. Hofmann, M. Manyage, "Derating of induction motors operating with a combination of unbalanced voltages and over or under voltages," IEEE Trans. Energy Conversion, vol.17, no.4, pp. 485- 491, Dec 2002.

[6] J. D. Kueck, M. Olszewski, D. A. Casada, J. Hsu, P. J. Otaduy, and L. M. Tolbert, "Assessment of methods for estimating motor efficiency, and load under field conditions," Oak Ridge National Laboratory Rep., ORNL/ TM-13165, 1996.

[7] "In-plant electric motor loading and efficiency techniques," Ontario Hydro Rep., TSDD-90-043, 1990.

[8] Bin Lu, T. G. Habetler, R. G. Harley, "A nonintrusive and in-situ motorefficiency estimation method using air-gap torque with considerations of condition monitoring," IEEE Trans. Ind. Appl., vol. 44, pp. 1666-1674, Dec. 2008.

[9] P. Pillay, V. Levin, P. Otaduy, J. Kueck, "In-situ induction motor efficiency determination using the genetic algorithm," IEEE Trans. Energy Convers., vol. 13, pp. 326-333, Dec 1998.

[10] A. Charette, J. Xu, A. Ba-Razzouk, P. Pillay, V. Rajagopalan, "The use of the genetic algorithm for in-situ efficiency measurement of an induction motor," in Conf. Rec. IEEE Power Engineering Society Winter Meeting, 2000, pp. 392-397.

[11] T. Phumiphak, C. Chat-uthai, "Estimation of induction motor parameters based on field test coupled with genetic algorithm," in Proc. IEEE Int. Conf. Power System Technology, 2002, pp. 1199- 120.

[12] T. Phumiphak, C. Chat-uthai, "An economical method for induction motor field efficiency estimation for use in on-site energy audit and management," in Proc. IEEE Int. Conf. Power System Technology, 2004, pp. 1250- 1254.

[13] Bin Lu, Cao Wenping; I. French, K. J. Bradley, T. G. Habetler, "Nonintrusive efficiency determination of in-situ induction motors using genetic algorithm and air-gap torque methods," in Conf. Rec. IEEE 42nd IAS Annual Meeting, 2007, pp. 1186-1192.

[14] M. S. Aspalli, S. B. Shetagar, S. F. Kodad, "Estimation of induction motor field efficiency for energy audit and management using genetic algorithm," in Proc. IEEE Int. Conf. Sensing Technology, 2008, pp. 440445 .

[15] P. Phumiphak, C. Chat-uthai, "Nonintrusive method for estimating field efficiency of inverter-fed induction motor using measured values," in Proc. IEEE Int. Conf. Sustainable Energy Technologies, 2008, pp. 580583.

[16] M. Cunkas, T. Sag, "Efficiency determination of induction motors using multi-objective evolutionary algorithms", Elsevier J. Advances in Engineering Software, vol. 41, pp. 255-261, Feb. 2010.

[17] A. Siddique, G. S. Yadava, B.Singh, "Effects of voltage unbalance on induction motors," IEEE Int. Symposium on Electrical Insulation, 2004, pp. 26- 29.

[18] Ching-Yin Lee, "Effects of unbalanced voltage on the operation performance of a three-phase induction motor," IEEE Trans. Energy Conversion, vol.14, pp. 202-208, Jun 1999.

[19] J. R. Gomez, E. C. Quispe, M. A. de Armas, P. R. Viego, "Estimation of induction motor efficiency in-situ under unbalanced voltages using genetic algorithms," IEEE Int. Conf. Electrical Machines, 2008, pp. 1-4.

[20] A.K. Ziarani, "Extraction of Non-stationary Sinusoids", Ph.D. dissertation, University of Toronto, Toronto, Canada, 2002.

[21] S. E. Zocholl, E. O. Schweitzer, A. Aliaga-Zegarra, "Thermal protection of induction motors enhanced by interactive electrical and thermal models," IEEE Trans. Power App. and Syst., vol. PAS-103, pp. 17491755, July 1984.

[22] IEEE Standard Test Procedure for Polyphase Induction Motors and Generators, IEEE Standard 112, 2004.

[23] B. W.Williams, J. K. Goodfellow, T. C. Green, "Sensorless speed measurement of inverter driven squirrel cage induction motors," in Proc. IEEE Int. Conf. Power Electronics and Variable-Speed Drives, 1991, pp. 297-300.

[24] Bin Lu, Cao Wenping, T. G. Habetler, "Error Analysis of MotorEfficiency Estimation and Measurement," in Conf. Rec. IEEE Power Electronics Specialists, 2007, pp.612-618.

[25] B. Herndler, P. Barendse, M.A. Khan, "Considerations for improving the non-intrusive efficiency estimation of induction machines using the air gap torque method," in Conf. Rec. IEEE Electric Machines \& Drives, 2011, pp.1516-1521.

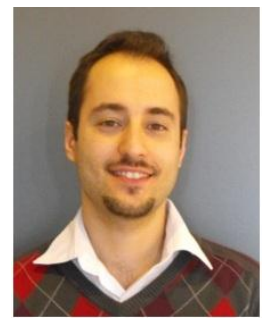

Arbi Gharakhani Siraki (S'07) received the B.S. degree in electrical engineering from Azad University, Tehran, Iran, in 2004 and the M.Sc. degree in electrical engineering from K.N.T University of Technology, Tehran, Iran, in 2007.

$\mathrm{He}$ is currently working toward the Ph.D. degree, in the Power Electronics and Energy Research Group, Department of Electrical and Computer Engineering of Concordia University, Montreal, Canada.

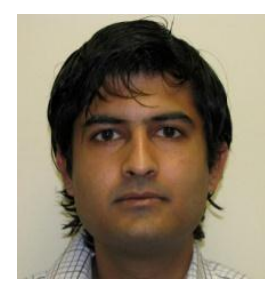

Chetan Gajjar ( $S^{\prime}$ 07) is currently working toward the M.Sc. degree, in Electrical Engineering in the Department of Electrical Engineering, University of Cape Town, South Africa.

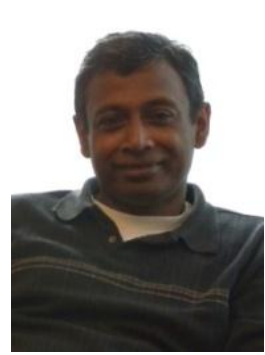

Pragasen Pillay (F'05) received the Bachelor's and Master's degrees in electrical engineering from the University of Kwa-Zulu Natal, Durban, South Africa, in 1981 and 1983, respectively, and the Ph.D. degree in electrical engineering from Virginia Polytechnic Institute and State University, Blacksburg, in 1987.

Currently, he is a Professor in the Department of Electrical and Computer Engineering, Concordia University, Montreal, Canada, where he holds the NSERC/Hydro Quebec Industrial Research Chair. 


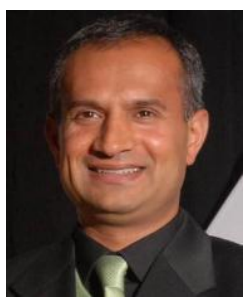

Mohamed Azeem Khan (M'07) received his BSc Eng, MSc and PhD degrees in Electrical Engineering from the University of Cape Town, South Africa. He worked for Eskom at Koeberg Nuclear Power Station as a Maintenance Engineer and as a System Engineer on the turbine and generator control systems. He successfully completed a course in Nuclear Engineering while at Eskom. He is currently a Senior Lecturer at the University of Cape Town. His research interests are in Electrical Machines, Drives and Renewable Energy Systems. He is currently involved in several research projects for Eskom and SANERI.

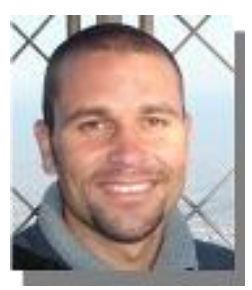

Paul Barendse (M'07) received his BSc Eng, MSc and $\mathrm{PhD}$ degrees in Electrical Engineering from the University of Cape Town, South Africa. He is currently a Senior Lecturer at the University of Cape Town. His research interests are in Condition monitoring, Drives, Fuel cells and energy efficiency. $\mathrm{He}$ is currently involved in several research projects for Eskom and SANERI. 